\title{
openheart The reduced cost of providing a nationally recognised service for familial hypercholesterolaemia
}

\author{
Robert Pears, ${ }^{1}$ Michael Griffin, ${ }^{2}$ Melanie Watson, ${ }^{3}$ Rebecca Wheeler, ${ }^{4}$ \\ Debbie Hilder, ${ }^{5}$ Beverley Meeson, ${ }^{4}$ Sallie Bacon, ${ }^{1}$ Christopher D Byrne ${ }^{6}$
}

To cite: Pears R, Griffin M, Watson $\mathrm{M}$, et al. The reduced cost of providing a nationally recognised service for familial

hypercholesterolaemia. Open Heart 2014;1:e000015. doi:10.1136/openhrt-2013000015

- Additional material is available. To view please visit the journal online (http://dx. doi.org/10.1136/openhrt2013-000015)

Received 6 December 2013 Revised 15 May 2014 Accepted 15 July 2014

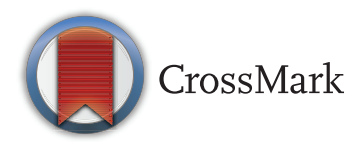

${ }^{1}$ Department of Public Health, Hampshire County Council, Winchester, UK

${ }^{2}$ Solutions for Public Health, Oxford, UK

${ }^{3}$ Wessex Clinical Genetic Centre, Southampton, UK

${ }^{4}$ West Hampshire CCG,

Eastleigh, Hampshire, UK

${ }^{5}$ Health Education Wessex,

Otterbourne, UK

${ }^{6}$ Southampton National Institute for Health Research, Biomedical Research Centre, University Hospital Southampton and University of Southampton,

Southampton, UK

Correspondence to Mr Robert Pears;

Robert.pears@hants.gov.uk

\section{ABSTRACT}

Objective: Familial hypercholesterolaemia (FH) affects 1 in 500 people in the UK population and is associated with premature morbidity and mortality from coronary heart disease. In 2008, National Institute for Health and Care Excellence (NICE) recommended genetic testing of potential $\mathrm{FH}$ index cases and cascade testing of their relatives. Commissioners have been slow to respond although there is strong evidence of cost and clinical effectiveness. Our study quantifies the recent reduced cost of providing a $\mathrm{FH}$ service using generic atorvastatin and compares NICE costing estimates with three suggested alternative models of care (a specialist-led service, a dual model service where general practitioners (GPs) can access specialist advice, and a GP-led service).

Methods: Revision of existing 3 year costing template provided by NICE for FH services, and prediction of costs for running a programme over 10 years. Costs were modelled for the first population-based FH service in England which covers Southampton, Hampshire, Isle of Wight and Portsmouth (SHIP). Population 1.95 million.

Results: With expiry of the Lipitor (Pfizer atorvastatin) patent the cost of providing a 10-year FH service in SHIP reduces by $42.5 \%$ ( $£ 4.88$ million on patent vs $£ 2.80$ million off patent). Further cost reductions are possible as a result of the reduced cost of DNA testing, more management in general practice, and lower referral rates to specialists. For instance a dual-care model with GP management of patients supported by specialist advice when required, costs £1.89 million.

Conclusions: The three alternative models of care are now $<50 \%$ of the cost of the original estimates undertaken by NICE.

\section{INTRODUCTION}

Familial hypercholesterolaemia (FH) affects an estimated 1 in 500 people, but the vast majority (85\%) of affected people in the UK are currently unaware of their status. ${ }^{1}$ Left untreated $50 \%$ of men have coronary heart disease by the time they are 50 years of age, and at least $30 \%$ of women by the time they

\section{KEY MESSAGES}

What is already known about this subject?

- Familial hypercholesterolaemia (FH) is an autosomal dominant condition affecting an estimated 1 in 500 people in the general population that causes premature cardiovascular disease. Despite the availability of genetic testing, $85 \%$ of people with $\mathrm{FH}$ are undiagnosed. National Institute for Health and Care Excellence (NICE) guidelines from 2008 describe a FH cascade testing and treatment programme which is not only clinically effective in diagnosing and treating $\mathrm{FH}$, but is also costeffective (Incremental Cost-Effectiveness Ratio of $£ 2676$ per quality-adjusted life-year (QALY) for DNA testing and cholesterol testing vs cholesterol testing only). Despite this guideline English National Health Service (NHS) commissioners have been reluctant to implement FH services, apparently because of concerns over affordability.

What does this study add?

- This study reassesses the cost of a 10-year FH service which identifies all undiagnosed $\mathrm{FH}$ carriers. By switching to treatment with generic statins and managing more $\mathrm{FH}$ care through general practice, the costs of FH services can be more than halved, compared to NICE's original cost models.

How might this impact on clinical practice?

- Population-based FH services are less expensive than previously thought. NHS commissioners should now prioritise the implementation of $\mathrm{FH}$ services. This would improve the care for people with $\mathrm{FH}$, reducing cardiovascular morbidity and mortality.

are 60 years. $^{2}$ In August 2008, National Institute for Health and Care Excellence (NICE) published a guideline for implementing genetic testing of index case and cascade testing of their relatives on the basis of compelling evidence of clinical efficacy and cost-effectiveness. ${ }^{1}$ Current evidence shows that if identified, patients with FH can be offered high-dose statins, which extend 
life by approximately 9 years. $^{3}$ NICE recommends cascade testing through families using a combination of low-density lipoprotein (LDL) cholesterol and DNA testing for patients with a definite or possible diagnosis of $\mathrm{FH}$ at an incremental cost-effectiveness ratio of $£ 2676$ per quality-adjusted life-year (QALY) compared to LDL cholesterol testing only. ${ }^{4}$ This cost per QALY is well below NICE's threshold for cost-effectiveness ( $£ 20000$ per QALY). FH cascade testing is, therefore, more cost and clinically effective than most other models of care provided by the NHS.

National FH services have been established in Northern Ireland, Scotland and Wales. ${ }^{5}$ In England there have been a number of successful research programmes in specialist centres ${ }^{6-8}$ and in 2013 there has seen a renewed interest in implementation of an $\mathrm{FH}$ service in the English NHS. The Cardiovascular Disease Outcomes Strategy includes an ambition that 'approximately 50\%' of English people with FH get diagnosed and treated appropriately with potent statins ${ }^{9}$ and in August 2013 NICE published FH quality standards. ${ }^{10}$ In policy terms commissioning $\mathrm{FH}$ services improves the allocative efficiency of the NHS (ie, the efficiency with which the NHS allocates resources). Yet despite this there were no population-based cascade testing programmes in England at the beginning of 2013. An important reason for this paradoxical situation is that Clinical Commissioning Groups (CCGs) consider new $\mathrm{FH}$ services to be unaffordable given their existing spending commitments and requirement to make quality innovation productivity and prevention savings.

This study aimed to establish the total cost of providing a 10-year FH service that involves genetic testing of index cases, cascade testing of relatives and annual patient reviews, for three different models of care. We used the NICE's $2009 \mathrm{FH}$ costing template ${ }^{11}$ to determine the affordability of a FH service for a population of 1.95 million people in Southampton, Hampshire, Isle of Wight and Portsmouth (SHIP). NICE estimated that full implementation of their guideline would take 510 years, but provided only a 3-year costing template, partly because it was unclear what atorvastatin would cost once its pharmaceutical patent owned by Pfizer expired in November 2011. Our study estimates the cost of a 10-year FH cascade testing programme using NICE's costs, and compares these to a revised lower cost service, once atorvastatin was widely available across the UK as a less expensive generic drug. We have also evaluated whether costs can be further reduced, without compromising clinical quality, by comparing three models of service delivery with varying amounts of support from specialists and general practice.

\section{METHODS}

Full details of the methodology can be found in the online supplementary technical appendix. NICE's 2009 costing template ${ }^{11}$ calculated the costs of the first 3 years of a FH service. The costing template was extended to cover the 10 years of a FH service which aims to identify all FH carriers in the SHIP area. Lipid-lowering medication costs were updated to take account of off patent atorvastatin. The costs of a 10-year FH service in SHIP were calculated first using NICE's 2009 costing template assumptions, but substituting the cost of on patent atorvastatin ( $£ 36774$ per annum with patients receiving either a 40 or $80 \mathrm{mg}$ dose) with generic simvastatin (£60.36 per annum with patients receiving a $80 \mathrm{mg}$ dose) (N.B. Since 2011, because of the higher risk of muscle damage with $80 \mathrm{mg} /$ day this dose is not recommended in clinical practice).

The NICE assumptions were then altered to compare three possible models of delivery which aim to reduce the costs of a FH service further. These models of delivery were considered with varying input from specialists and GPs:

1. The first model considered was a specialist-led model. This model was similar to the NICE model with the exception that a lower proportion of patients would have annual reviews in secondary care.

2. The second model involved primary care taking responsibility for the entire adult FH care pathway. In this model a third fewer patients would be referred to a FH specialist (locally this means a lipidologist) and all patients would be reviewed annually by their GP.

3. The final model was a 'dual care' model where primary care would manage the majority of the $\mathrm{FH}$ cascade testing pathway. In this final model, GPs would be able to refer patients to lipidologists if they needed further advice about management, or to genetic services, when advice on cascade testing was needed because a genetic mutation had not been identified.

The details of how the three delivery models differ are shown in figure 1, table 2 and the online supplementary technical appendix.

\section{RESULTS}

\section{The costs of a $\mathbf{1 0}$-year programme}

The 10-year model was run twice for SHIP, once with atorvastatin costing $£ 36774$ (40 or $80 \mathrm{mg}$ in the NICE model) per patient per annum and then with atorvastatin at the 2009 cost of generic simvastatin $80 \mathrm{mg}$ which was $£ 60.36$ per patient per annum. (see table 1 and figure 2). The gross cumulative cost of the $\mathrm{FH}$ service was $£ 5527750$ with atorvastatin on patent or £3 534750 over the 10-year programme with atorvastatin off patent. The net cost of the FH service was $£ 4876321$ with atorvastatin on patent or $£ 2804150$ with atorvastatin off patent incorporating saved costs from avoided cardiac events (see table 1). With generic atorvastatin the $\mathrm{FH}$ service becomes $42.5 \%$ less expensive.

Between year 1 and year 7, 3547 people participate in the FH service of which $470(13.3 \%)$ are index cases and $3077(86.7 \%)$ are relatives. The 10-year costings 

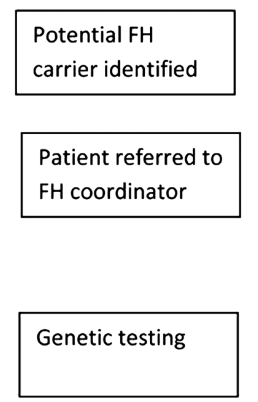

Follow up

Treatment

decisions
Potential FH index case identified by

GP, lipidologist or cardiologist

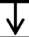

Patient assessed by FH Coordinator

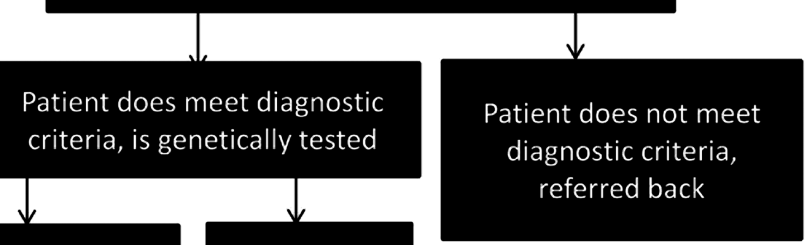

Mutation identified.

First, second, and third

degree relatives invited

to cascade testing

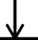

Treatment: in GP led

model determined by

GP. In dual care model

$80 \%$ determined by GP,

$20 \%$ by specialist. In

specialist led model $70 \%$

determined by GP, 30\%

by specialist.
Mutation

not

identified.

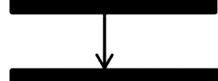

Management

based on

phenotype.

Identification

of phenotype

in relatives

Figure 1 Care pathway for suspected patients with familial hypercholesterolaemia, comparing three alternative models of delivery.

demonstrate that the cost of a $\mathrm{FH}$ service does not rise year on year as might be suggested by NICE's 3-year costing template. There were predicted peaks in cost during year 3 ( $£ 496000$ with atorvastatin on patent and $£ 338000$ off patent) and in year 7 (£615 000 with atorvastatin on patent and $£ 340000$ off patent). Our modelling predicts that it takes 8 years for the investment in a $\mathrm{FH}$ service to be fully realised in terms of avoided cardiac events. In year 1 each cardiac event avoided cost $£ 116000$ with atorvastatin on patent or $£ 95000$ off patent. From year 8 onwards each cardiac event avoided cost $£ 38000$ with atorvastatin on patent or $£ 18000$ off patent.

Importantly, the cost of drug therapy was the most expensive component of the programme, $£ 3.74$ million $(67.7 \%)$ with atorvastatin on patent or $£ 1.75$ million $(49.5 \%)$ off patent. This was followed by cascade testing ( $\$ 910000$ in both models), annual patient review meetings (£742 000 in both models) and specialist referrals
(£135000 in both models). In the off patent model, cascade testing accounts for $25.7 \%$ of costs, annual reviews $21 \%$ of costs and specialist referrals $3.8 \%$. After cascade testing finishes in year 7 , the major expense of a $\mathrm{FH}$ service is the annual review. The avoidance of cardiac events saved $£ 651000$ over a decade, reducing the cost of the programme by $11.8 \%$ with atorvastatin on patent or $20.7 \%$ with atorvastatin off patent.

\section{Comparing the costs of the three models of delivery}

Spurred on by the widespread availability of generic and less expensive atorvastatin prescribing, clinicians and managers in SHIP further modified local costs in the NICE template. Three alternative models of delivery were devised (specialist led, dual care and GP led) to determine whether a $\mathrm{FH}$ service could be made less expensive and even more affordable.

Regardless of the three models of delivery for adults, all paediatric referrals would continue to follow NICE's 
recommended care pathway involving specialist referral. The following changes to the default assumptions in the NICE costing template for adults (see table 2).

With the exception of a higher local cost for DNA testing for an identified mutation ( $£ 75$ vs NICE's £50) all the changes made to the NICE costings reduced the cost of the SHIP programme. The reduction in costs for simvastatin $80 \mathrm{mg}$ ( $£ 60.36$ to $£ 29.33$ per annum) and atorvastatin (£367.74 per annum to £25.16 for $40 \mathrm{mg}$ or $£ 45.49$ for $80 \mathrm{mg}$ ) have dramatically reduced the cost of drug treatment. With generic atorvastatin available it is now unjustifiable that $40 \%$ of patients with $\mathrm{FH}$ should receive rosuvastatin (28 days of $20 \mathrm{mg}$ rosuvastatin currently costs £26.02 in the UK, compared with $20 \mathrm{mg}$ atorvastatin costing $£ 1.71$, but without additional proven clinical benefit). In all models of delivery it is assumed that the majority will be switched to atorvastatin. The three delivery models diverge from NICE by starting with a very high percentage of annual reviews being delivered in general practice (in the case of the GP-led model $100 \%)$. In the dual-care and GP-led models a third fewer patients $(20 \%$ vs $30 \%)$ are referred to a $\mathrm{FH}$ specialist, though in all models it is assumed that $10 \%$ of patients will still be referred to a cardiologist. It was also decided that a SHIP programme would not have the same scope to identify relatives as a national programme. This followed a 2007 national audit ${ }^{8}$ which showed that a third $(34 \%)$ of relatives lived outside lipid clinic catchment areas. As SHIP is larger than a lipid clinic catchment area, but relatively small compared to England, it was assumed that a quarter $(25 \%)$ fewer firstdegree, second-degree and third-degree relatives would be identified.

Local modifications to the NICE costing template meant that all three models of delivery were more affordable than the original NICE model (see table 3 and figure 3).

As the SHIP FH service is stand alone, as opposed to being part of a national FH service, fewer relatives participate in cascade testing as a proportion will live out of area. In the SHIP models 2307 relatives participate compared to 3077 in the NICE model, a 25\% reduction. With fewer FH carriers identified there are fewer cardiovascular events avoided. As a result it is anticipated that over 10 years 25 revascularisations will be avoided compared to 37 as part of a national programme (a $32.4 \%$ reduction) and 51 myocardial infarctions avoided compared to 68 as part of a national programme (a 25\% reduction).

The local modifications to the NICE costing template reduce the cost of a $\mathrm{FH}$ service substantially, but not to the same extent as the introduction of generic atorvastatin. Generic atorvastatin reduces the cost of a 10-year service by $42.5 \%$ ( $£ 4876321$ to $£ 2804150$ ). Compared to NICE costing estimates with generic atorvastatin: the specialist led model reduces 10-year costs by $27.2 \%$ ( $£ 204150$ to $£ 2041000$ ); the dual-care model by $32.5 \%$ ( $£ 2804150$ to $£ 1894000$ ); and the GP-led model by $35.8 \% \%$ (£2 804150 to $£ 1801000$ ). The NICE costings with atorvastatin on patent are 2.4-fold greater than the specialist-led model, 2.6-fold greater than the dual-care model and 2.7-fold greater than the GP-led model.

The variation in costs between local models result mainly from number of patients referred to specialists in secondary care (see table 4). This affects the costs of cascade testing depending on whether it is initiated by a lipidologist, specialist referrals (the proportion of patients managed in general practice) and annual review meetings (whether these are carried out in general practice at $£ 36.28$ each or by a specialist at $£ 97.87$ ). This explains why the costs of models tend to converge once cascade testing is completed in year 7 when there are fewer opportunities for patients to see specialists. The difference in cost between the most expensive option, specialist led, and the cheapest option, GP led, is a relatively modest $£ 240000$ over a 10-year programme.

Currently the cost of DNA testing in SHIP is £250 for index cases and $£ 70$ for previously identified mutations. With recent developments in sequencing platforms the cost of hardware has fallen and potential sequencing throughput has increased. The costs of DNA testing are likely to fall considerably over the next 2 years. The expectation is that the costs of DNA testing will reduce to $£ 200$ for index cases and $£ 50$ for their relatives relatively quickly. If this occurs the cost of the year $3 \mathrm{FH}$ service would be $£ 221800$ (a further $7.6 \%$ reduction in cost) for the specialist-led model, $£ 194000$ (a 6.1\% reduction) for the dual-care model or $£ 180000$ (a $9.3 \%$ reduction) for the GP-led model. Further reductions in the cost of DNA testing are possible at a later stage of the programme.

\section{DISCUSSION \\ Principal findings}

Our results show that each of these models of service delivery can be provided for less than half the cost of the original estimates undertaken by NICE. Expiry of the Pfizer patent on proprietary Lipitor restricting use of atorvastatin in November 2011, and options to modify delivery models have made providing a $\mathrm{FH}$ service much more affordable than suggested by the NICE 2009 costing template. Once the savings from avoided cardiac events are taken into account, a 10-year programme for a population of 1.95 million people costs $£ 2.80$ million, $42.5 \%$ less than the $£ 4.88$ million it would have cost if atorvastatin remained on patent. Over 10 years the $\mathrm{FH}$ service with atorvastatin off patent has drug therapy costs of $£ 1.75$ million (49.5\% of programme costs and still the most costly component of the programme). Cascade testing costs $£ 910000$ (25.7\% of the programme), annual reviews costs of $£ 742000(21 \%)$ and specialist review costs of $£ 135000(3.8 \%)$. There are $£ 651000$ savings from 
Table 1 Costs and clinical benefits of a 10-year FH service in the SHIP area. Costs with atorvastatin on and off patent compared in £'000s

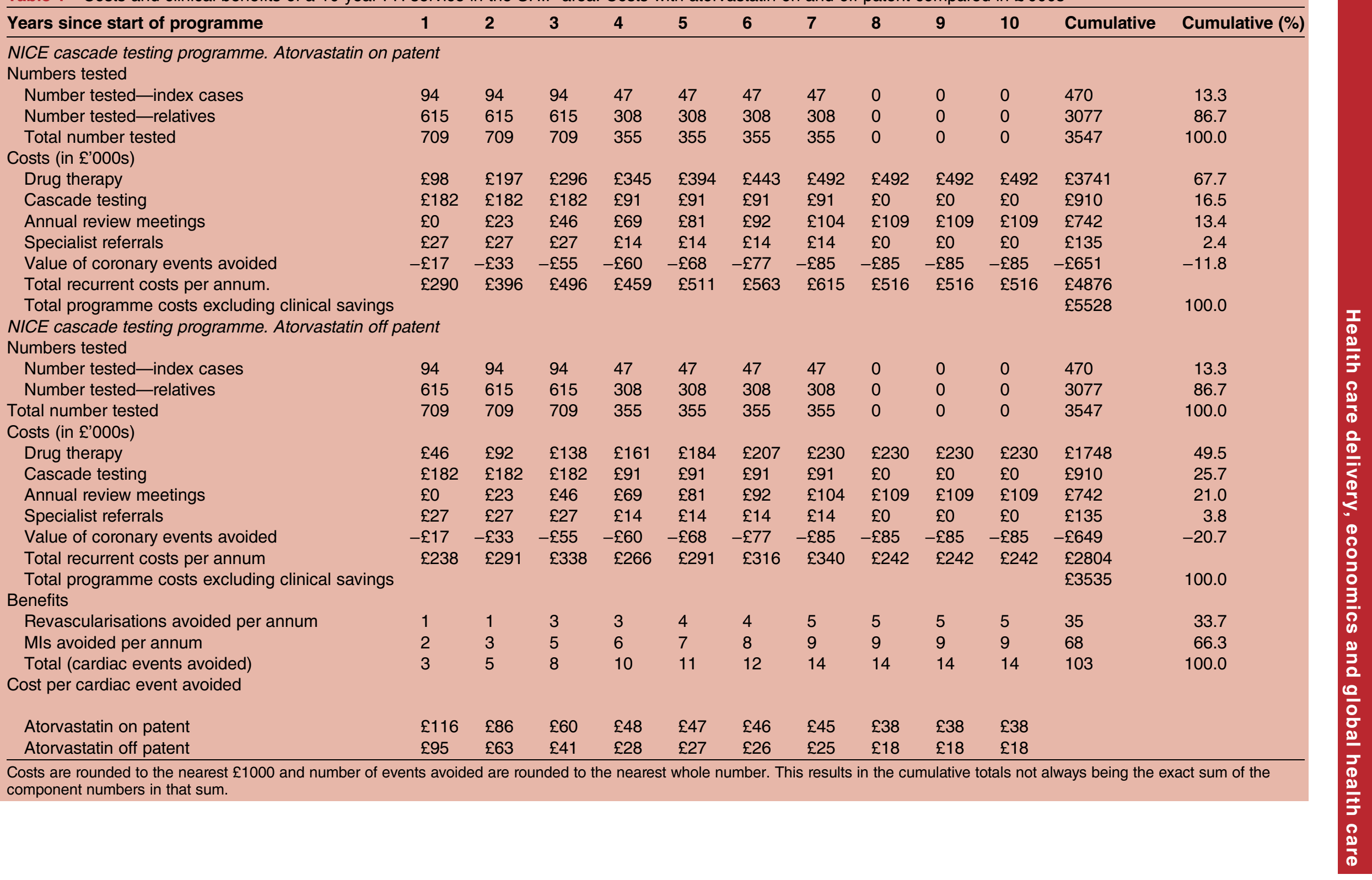

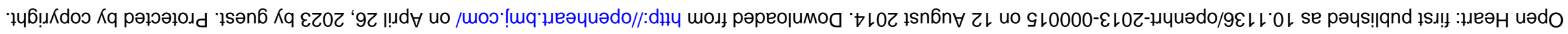


Table 2 SHIP modifications to the NICE template

\begin{tabular}{|c|c|c|c|c|}
\hline $\begin{array}{l}\text { Template } \\
\text { component }\end{array}$ & Item & NICE & Local modifications & Reason for modification \\
\hline \multirow[t]{3}{*}{ Drug treatment } & $\begin{array}{l}\text { Proportions receiving } \\
\text { statins }\end{array}$ & $\begin{array}{l}20 \% \text { simvastatin, } 40 \% \\
\text { atorvastatin, } 40 \% \\
\text { rosuvastatin }\end{array}$ & $\begin{array}{l}20 \% \text { simvastatin, } 72 \% \text { atorvastatin, } 8 \% \\
\text { rosuvastatin }\end{array}$ & $\begin{array}{l}\text { Atorvastatin has lost exclusivity. Medicines } \\
\text { management discourages prescribing of } \\
\text { rosuvastatin }\end{array}$ \\
\hline & Cost of statins & $\begin{array}{l}\text { Simvastatin } 80 \mathrm{mg} £ 60.36 \\
\text { per annum }\end{array}$ & Simvastatin 80 mg £29.33 per annum & April 2013 drug tariff \\
\hline & & $\begin{array}{l}\text { Atorvastatin } 40 \mathrm{mg} \text { or } 80 \mathrm{mg} \\
£ 367.74 \text { per annum }\end{array}$ & $\begin{array}{l}\text { Atorvastatin } £ 35.33 \text { per annum (average of } \\
£ 25.16 \text { for } 40 \mathrm{mg} \text { and } £ 45.49 \text { for } 80 \mathrm{mg} \text { ) }\end{array}$ & April 2013 drug tariff \\
\hline \multirow[t]{3}{*}{ Cascade testing } & $\begin{array}{l}\text { Average number of } \\
\text { relatives identified }\end{array}$ & $\begin{array}{l}4 \text { first degree, } 8 \text { second } \\
\text { degree, } 12 \text { third degree }\end{array}$ & $\begin{array}{l}3 \text { first degree, } 6 \text { second degree, } 9 \text { third } \\
\text { degree }\end{array}$ & $\begin{array}{l}\text { SHIP programme will not benefit from relative } \\
\text { identification in rest of England }\end{array}$ \\
\hline & $\begin{array}{l}\text { DNA test to identify } \\
\text { indivudal mutation }\end{array}$ & $£ 400$ & $£ 250$ & Cost of sequencing has fallen \\
\hline & $\begin{array}{l}\text { DNA test for previously } \\
\text { identified mutation }\end{array}$ & $£ 50$ & $£ 70$ & Local cost higher \\
\hline $\begin{array}{l}\text { Annual review } \\
\text { meeting }\end{array}$ & $\begin{array}{l}\text { Proportion followed up } \\
\text { in general practice }\end{array}$ & $\begin{array}{l}28 \% \text { in year } 1,52 \% \text { in year } \\
2,64 \% \text { in year } 3\end{array}$ & $\begin{array}{l}80 \% 3 \text { in specialist and dual models. } \\
100 \% \text { in GP-led model }\end{array}$ & $\begin{array}{l}\text { No local research programme established so } \\
\text { programme can start with most/all follow-up by } \\
\text { GPS }\end{array}$ \\
\hline \multirow[t]{2}{*}{$\begin{array}{l}\text { Specialist } \\
\text { referrals }\end{array}$} & $\begin{array}{l}\text { Proportion referred to } \\
\text { FH specialist }\end{array}$ & $30 \%$ & $\begin{array}{l}30 \% \text { in specialist model, } 20 \% \text { in dual-and } \\
\text { GP-led model }\end{array}$ & $\begin{array}{l}\text { With exception of specialist model there is great } \\
\text { emphasis on care in general practice }\end{array}$ \\
\hline & $\begin{array}{l}\text { Cost of referreal to } \mathrm{FH} \\
\text { specialist }\end{array}$ & $£ 355.47$ & $£ 322.00$ & Local tariff \\
\hline
\end{tabular}




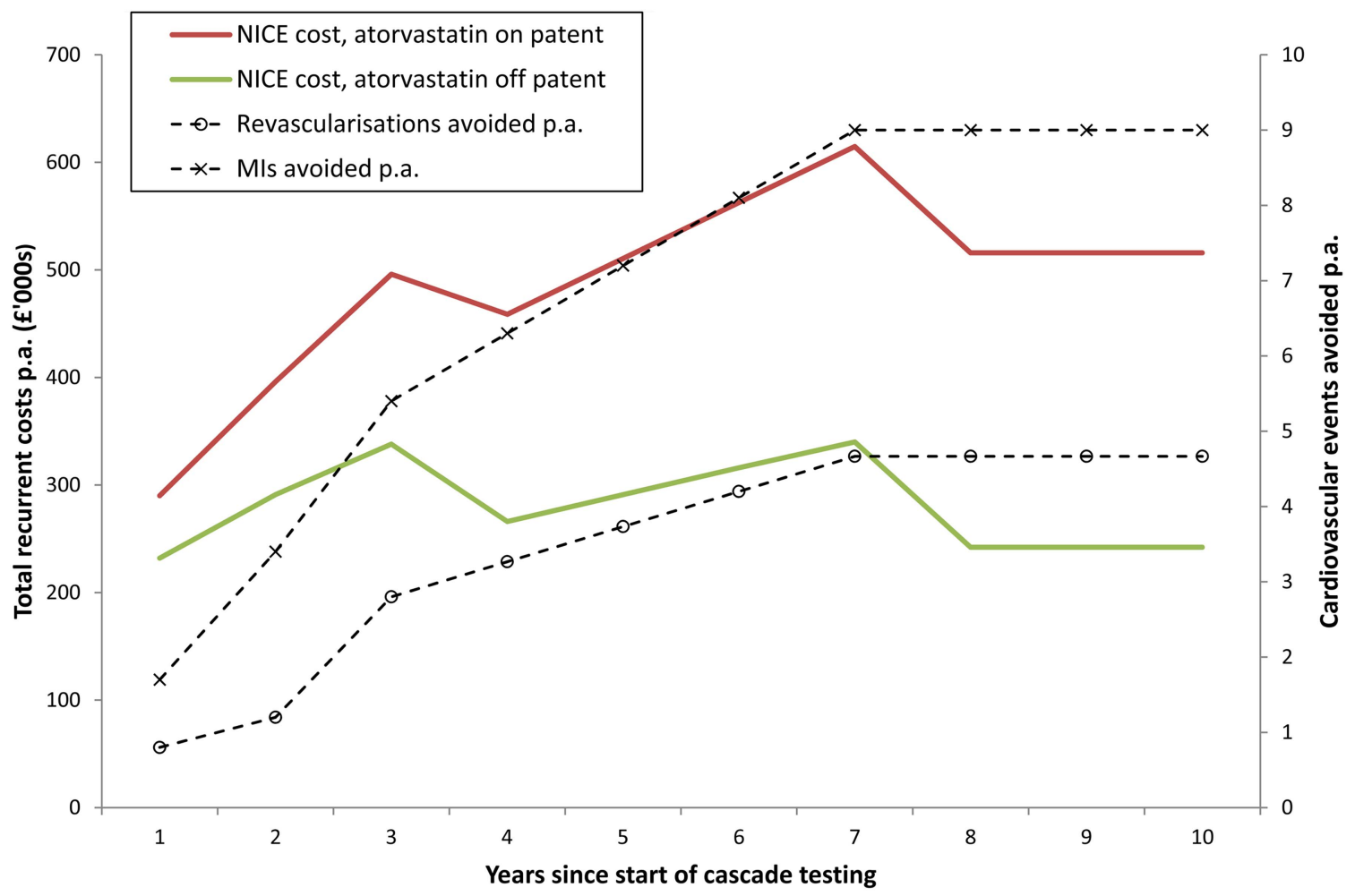

Figure 2 Evolution over 10 years of the costs and benefits of a familial hypercholesterolaemia service in Southampton, Hampshire, Isle of Wight and Portsmouth area with atorvastatin on and off patent.

avoided cardiac events, saving $20.7 \%$ of the costs of the programme. Three models of delivery devised in SHIP (population 1.95 million), demonstrate that further savings are possible. Costs could also be reduced by switching patients from Astra Zeneca owned Crestor (rosuvastatin) which is protected by a substance patent until 8 January 2016, to genetic atorvastatin, utilising technologically improved cheaper DNA testing, holding more annual reviews in general practice and by better management in primary care. Compared to NICE costing with atorvastatin off patent, the specialist-led model is $27.2 \%$ less expensive, the dual care model is $32.5 \%$ less expensive and the GP-led model is $35.8 \%$ less expensive. Reductions

Table 3 Comparison of original NICE costings for SHIP with modified costings for the three alternative models of delivery in $£^{\prime} 000$ s

\begin{tabular}{|c|c|c|c|c|c|c|c|c|c|c|c|}
\hline Years since start of programme & 1 & 2 & 3 & 4 & 5 & 6 & 7 & 8 & 9 & 10 & Cumulative \\
\hline \multicolumn{12}{|l|}{ Numbers tested NICE model } \\
\hline Number tested-index cases & 94 & 94 & 94 & 47 & 47 & 47 & 47 & 0 & 0 & 0 & 470 \\
\hline Number tested—relatives & 615 & 615 & 615 & 308 & 308 & 308 & 308 & 0 & 0 & 0 & 3077 \\
\hline Total number tested & 709 & 709 & 709 & 355 & 355 & 355 & 355 & 0 & 0 & 0 & 3547 \\
\hline \multicolumn{12}{|l|}{ Costs (in £000’s) } \\
\hline NICE cost, atorvastatin on patent & $£ 290$ & $£ 396$ & $£ 496$ & $£ 459$ & $£ 511$ & $£ 563$ & $£ 615$ & $£ 516$ & $£ 516$ & $£ 516$ & $£ 4876$ \\
\hline NICE cost, atorvastatin off patent & $£ 238$ & $£ 291$ & $£ 338$ & $£ 266$ & $£ 291$ & $£ 316$ & $£ 340$ & $£ 242$ & $£ 242$ & $£ 242$ & $£ 2804$ \\
\hline \multicolumn{12}{|l|}{ Numbers tested SHIP Models } \\
\hline Number tested-index cases & 94 & 94 & 94 & 47 & 47 & 47 & 47 & 0 & 0 & 0 & 470 \\
\hline Number tested-relatives & 461 & 461 & 461 & 231 & 231 & 231 & 231 & 0 & 0 & 0 & 2307 \\
\hline Total number tested & 555 & 555 & 555 & 278 & 278 & 278 & 278 & 0 & 0 & 0 & 2777 \\
\hline \multicolumn{12}{|l|}{ Costs (in £000’s) } \\
\hline Specialist led & $£ 170$ & $£ 203$ & $£ 240$ & $£ 195$ & $£ 213$ & $£ 232$ & $£ 250$ & $£ 179$ & $£ 179$ & $£ 179$ & $£ 2041$ \\
\hline Dual-care model & $£ 137$ & $£ 170$ & $£ 207$ & $£ 196$ & $£ 197$ & $£ 215$ & $£ 234$ & $£ 179$ & $£ 179$ & $£ 179$ & $£ 1894$ \\
\hline GP led & $£ 131$ & $£ 162$ & $£ 198$ & $£ 187$ & $£ 187$ & $£ 205$ & $£ 222$ & $£ 170$ & $£ 170$ & $£ 170$ & $£ 1801$ \\
\hline
\end{tabular}




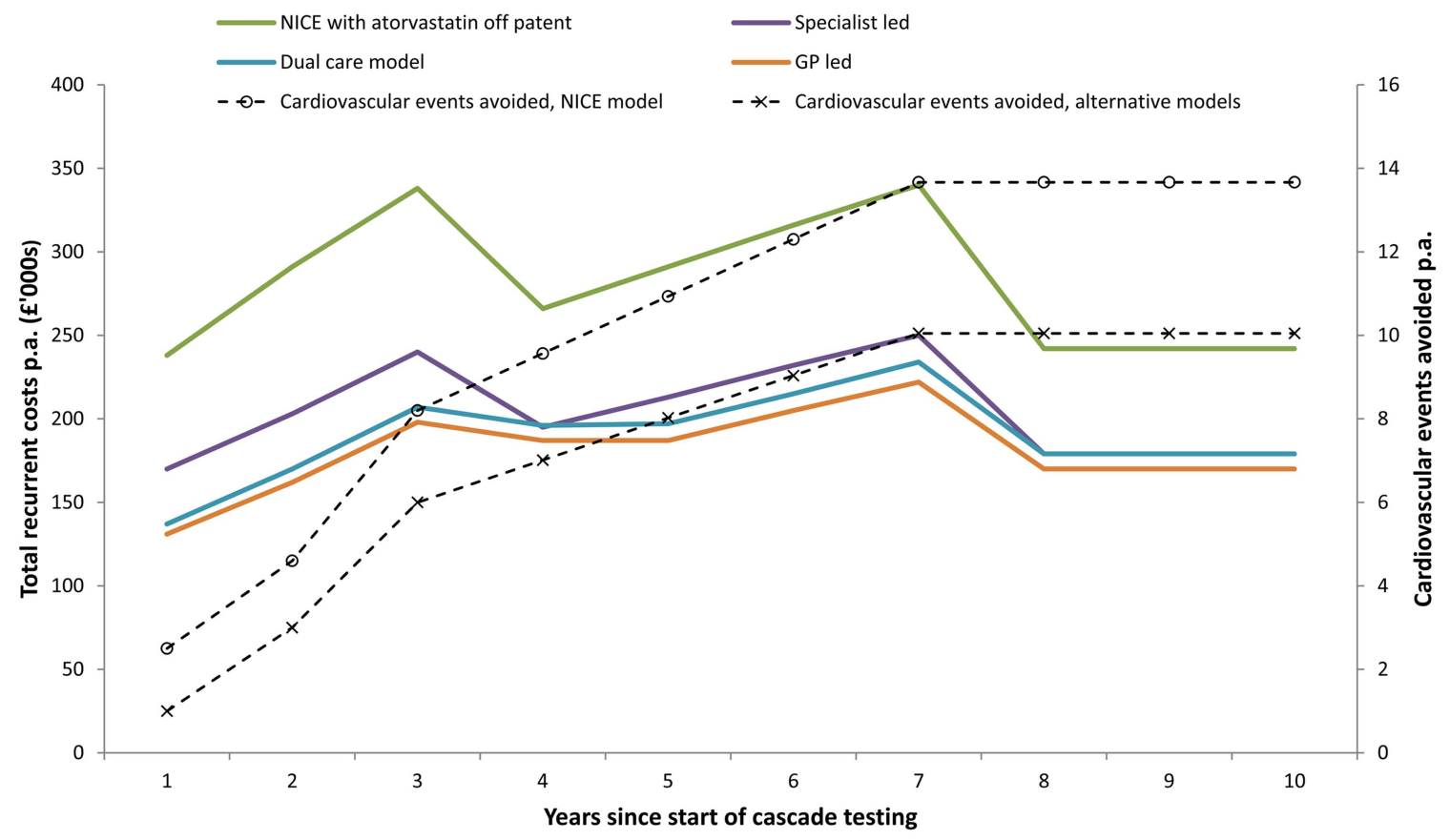

Figure 3 Evolution over 10 years of costs and benefits of familial hypercholesterolaemia service in Southampton, Hampshire, Isle of Wight and Portsmouth area: National Institute for Health and Care Excellence with atorvastatin off patent compared to three alternative models of delivery.

in the cost of DNA testing over the next 2 years are likely to make FH services even more affordable.

\section{Strengths and limitations of study}

Policy makers, clinicians and clinical commissioners are already convinced that $\mathrm{FH}$ cascade testing is both highly clinically effective and cost-effective. However, a strength of our study is that it addresses a key, pragmatic aspect of commissioning decisions that is not usually addressed in economic evaluations of FH services: that is, service costs. FH services are more affordable now than originally envisaged by NICE but to be more comprehensive our study should have compared the affordability of $\mathrm{FH}$ services with other services in the cardiovascular and cardiology specialty. To have carried out this would have enabled commissioners to prioritise more easily and this should be an area of further research. Having modified the original NICE costing model (table 2) it was not possible to calculate QALY gains for the SHIP models compared to NICE's cost-effectiveness analysis. Despite the lack of revised incremental cost-effectiveness ratios this study's considerable reduction in delivery costs between the NICE and SHIP delivery models implies an improvement in the cost-effectiveness. Another limitation, is that our study does not include a sensitivity analysis which is a concern when comparing costs of three alternative models of delivery. Furthermore, a number of the assumptions used in our study can be questioned. However, that said, by extending NICE's helpful 3-year costing template to 10 years, commissioners can estimate the full cost of a more complete programme. This evolution of costs is easier to estimate now that atorvastatin is off patent, but it necessitates more assumptions than NICE's original model. In particular the pattern of index

Table 4 Comparison of cost components of alternative delivery models over 10 year (years in £'000s)

\begin{tabular}{|c|c|c|c|c|c|c|}
\hline \multirow{2}{*}{$\begin{array}{l}\text { Costs (in £'000s) } \\
\text { Cost component }\end{array}$} & \multirow{2}{*}{$\begin{array}{l}\text { Specialist led } \\
\text { Cost }\end{array}$} & \multirow[b]{2}{*}{$\begin{array}{l}\text { Percentage } \\
\text { of cost }\end{array}$} & \multicolumn{2}{|c|}{ Dual-care model } & \multirow{2}{*}{$\begin{array}{l}\text { GP led } \\
\text { Cost }\end{array}$} & \multirow[b]{2}{*}{$\begin{array}{l}\text { Percentage } \\
\text { of cost }\end{array}$} \\
\hline & & & Cost & $\begin{array}{l}\text { Percentage } \\
\text { of cost }\end{array}$ & & \\
\hline Cascade testing & $£ 620$ & 25.4 & $£ 500$ & 21.7 & $£ 470$ & 22.4 \\
\hline Drug therapy & $£ 1055$ & 43.2 & $£ 1055$ & 45.9 & $£ 1055$ & 50.3 \\
\hline Specialist referrals & $£ 85$ & 3.5 & $£ 60$ & 2.6 & $£ 60$ & 2.9 \\
\hline Annual review meetings & $£ 685$ & 28.0 & $£ 685$ & 29.8 & $£ 515$ & 24.5 \\
\hline $\begin{array}{l}\text { Value of coronary events } \\
\text { avoided }\end{array}$ & $-£ 290$ & -11.9 & - & -12.6 & $-£ 290$ & -13.8 \\
\hline Total recurrent costs per annum & $£ 2155$ & 88.1 & $£ 2010$ & 87.4 & $£ 1809$ & 86.2 \\
\hline $\begin{array}{l}\text { Total programme costs excluding } \\
\text { clinical savings }\end{array}$ & $£ 2445$ & 100.0 & $£ 2300$ & 100.0 & $£ 2100$ & 100.0 \\
\hline
\end{tabular}


case DNA testing is assumed to cover $20 \%$ of index cases in years $1-3$ and $10 \%$ in years $4-7$. This estimate may not be truly accurate. Locally lipid clinics have lists of suspected patients with $\mathrm{FH}$ which have led to an initial rush of DNA testing. It is possible that GP practices will not refer patients into the new service to the extent that was anticipated. This study has highlighted the potential for further reductions in DNA testing costs. In fact some costs may increase, but these have not been factored into the analysis, for instance the cost of specialist appointments or new generation lipid lowering drugs. ${ }^{12}$ Problematically for commissioners, the assumptions in the model are difficult to evaluate retrospectively. Commissioners will not benefit from being able to view a FH budget line. In practice most activity will be subsumed into larger budgets, for instance Quality and Outcomes Framework, phlebotomy and genetic testing. Commissioners are not in the position to agree funding for a 10-year programme, but rather fund on an annual basis. If funding were stopped prematurely, it is reasonable to anticipate there would be fewer avoided cardiac events.

The three alternative delivery models offer creative ways for the NHS to provide FH services at a lower cost than the original NICE model. The models of service delivery suggest that further savings are possible, above and beyond, the use of less expensive generic atorvastatin. We suggest the findings of our study are highly transferrable to other parts of England, as medication costs are the same and other cost are likely to be similar. The adjustments made to the NICE model in SHIP are listed in table 2 but can be further refined depending on local circumstances. Within SHIP, there was considerable debate about the extent to which the alternative models were compliant with NICE quality standards, particularly access to specialists. It was felt that the GP-led model provided patients with insufficient support, and consequently even though that model was the cheapest option, it was rejected by CCGs. To compensate for decreased access to lipidologists, geneticists and cardiologists, it has been necessary to create $\mathrm{FH}$ coordinator posts, the full costs (an experienced nurse) of which are not captured by the nursing time allocated in the original NICE model or this study. The FH coordinator has to set up the new service, train GPs, assess the appropriateness of referrals, liaise with specialists, travel between clinics and participate in continued professional development. Locally it is thought that one FH coordinator post is needed per 1 million of the population. Further details about the SHIP FH service are presented in box 1 .

\section{Implications of the study}

Local modifications to the NICE FH care pathway have implications for clinical effectiveness. The average number of relatives identified through index cases had
Box 1 Southampton, Hampshire, Isle of Wight and Portsmouth (SHIP) Wessex Familial Hypercholesterolaemia Cascade Testing Service

The SHIP Wessex Familial Hypercholesterolaemia Cascade Testing Service is overseen by a steering committee comprising of:

A Chair and representatives from: Commissioners from the eight Community Commissioning Groups within SHIP (including clinicians involved in cardiovascular risk reduction), Heart UK, lipidologists from centres around the region managing patients with $\mathrm{FH}$, public health clinicians involved in cardiovascular health, genetics counselling service involved in counselling of probands and relatives.

- Patients are informed about the Wessex FH Cascade Testing Service in clinic by either the lipidologist or general practitioner (GP) using the locally modified Simon Broome FH diagnostic criteria (see box 2)

- Patient's details sent to the Wessex Genetic counselling service

- Letter of introduction is sent by the Wessex Genetic counselling service to patient informing them of their referral to the Wessex FH Cascade Testing Service. Initial contact with the service is made by letter to acknowledge referral and to offer an appointment to meet with a genetic counsellor who arranges genetic testing after discussion with the patient (proband).

- There are two methods for contacting relatives 'Direct' or 'Family contact'. These options are discussed with the patient (proband) in their clinic appointment.

- A summary letter following each clinic appointment is sent to the patient (proband) and all relatives with agreed actions, and is copied to GP and/or referring clinican.

- Direct contact: involves the patient (proband) providing the healthcare professionals with the names and addresses of their relatives and the patient taking responsibility for contact.

- Family contact: involves the healthcare professional providing a 'to whom it may concern letter' to support the patient (proband) in this process.

N.B. A mix of approaches is sometimes needed within families and the best option is discussed on an individual patient basis. Telephone contact is only be made with prior agreement from patients (probands) and their families.

The Wessex FH Cascade Testing Service is using the FH-specific PASS Clinical software (licences supported for 3 years by Astra Zeneca). (PASS Clinical software has been successfully used in several other FH screening programmes before, including Wales and The Netherlands. HEART UK supports the use of PASS for FH cascade testing in their report, 'Saving Lives, Saving Families').

Regular FH clinics started in October 2013. SHIP's first FH specialist nurse left in October after only 4 months in post. From April 2014 three new FH specialist nurses/genetic counsellors, two of which are part funded by the British Heart Foundation, should join the service allowing a large increase in service capacity. This will enable the service to be launched formally in general practice. Since the soft launch of the service referrals into the $\mathrm{FH}$ service have increased from one from a lipidologist in June 2013 to 52 in December 2013, 4 $(7.7 \%)$ of which were from GPs and the rest from lipidologists. Separate paediatric clinics have identified $30 \mathrm{FH}$ carriers up to December 2013. Numbers of referrals will continue to grow as a result of cascade testing. 
Box 2 Locally modified Simon Broome FH diagnostic criteria

Refer for cascade genetic testing if the following criteria are present:

Possible FH

Total $\mathrm{LDL}>5.5 \mathrm{mmol} / \mathrm{L}$ in adult AND a triglyceride concentration less than $4.0 \mathrm{mmol} / \mathrm{L}$ (measurements either pretreatment or highest on treatment)

PLUS ONE OF THE FOLLOWING:

(1) Family history of myocardial infarction before age 50 in second-degree relative or before age 60 in first-degree relative

(2) Family history of raised total cholesterol concentration above $8.0 \mathrm{mmol} / \mathrm{L}$ in first-degree or second-degree relative

Definite FH

The above criteria plus Tendon xanthomata (or evidence of these in first-degree or second-degree relatives)

And/or DNA-based evidence of an low-density lipoprotein (LDL) receptor mutation, familiar receptor defective apo-B100, or a PCSK 9 mutation in patient or first-degree or second-degree relative.

Note: Consider the diagnosis if LDL cholesterol substantially elevated (ie, $>6.0 \mathrm{mmol} / \mathrm{L}$ ) even in the absence of a personal or family history of coronary disease.

to be reduced as a SHIP programme would not be embedded in a national programme. The expectation is that referrals to FH specialists are restricted in the dualcare and GP-led models. GPs have concerns that the new FH services could increase referrals to lipidologists. To limit this risk locally, the $\mathrm{FH}$ coordinator will assess the appropriateness of referrals into the new service and discuss with lipidologists where necessary. Fewer annual reviews in secondary care for all the SHIP models of delivery reduce access to specialists further and the amount of access to specialists is responsible for the main differences in costs between the models. As NICE makes clear in its costing report, GP costs relating to FH are hidden to commissioners, but this service places a small extra workload on busy local GPs.

Favourable costings were not perhaps the only factor that persuaded GP commissioners in SHIP to invest in FH services, though they did help. From 2008 when NICE published its FH guidance, local champions from general practice, public health, lipidology, genetics and management have pushed for a FH service. Many papers, meetings, presentations and false starts followed. It was difficult to get agreement across the four Primary Care Trust (PCTs) covering our region, and following the Health and Social Care Act 2012, agreement had to be reached across eight local CCGs. However, after several meetings lead GP commissioners were persuaded that FH was an opportunity for CCGs to commission a novel service for SHIP and once one CCG had agreed in our region the precedent was set for all to follow. Locally it was decided to implement the dual-care model, even though this was not the least expensive, but because it was felt necessary that this would provide good use of local specialist expertise in $\mathrm{FH}$ management. Once funding was agreed a whole new set of logistic challenges emerged which are being met as described in box 1 .

\section{Conclusions}

Our modelling estimates show that the three presented alternative models of care are now $<50 \%$ of the cost of the original estimates undertaken by NICE. Our work provides a framework for NICE to consider reissuing its costing template for implementation of an $\mathrm{FH}$ service. By using the latest statin costs, by reducing the proportion of patients prescribed more expensive proprietary-owned rosuvastatin (Crestor), and by managing more patients with $\mathrm{FH}$ in primary care, providing an FH service is now much more affordable than predicted by NICE in 2008 .

Acknowledgements This work and the success of achieving a Commissioned service across SHIP would not have been possible without the hard work of many people. The authors thank all who helped. The authors thank specifically Martin Allaby from SPH who helped develop the first revised economic model; to Karol Ambramczuk for formatting the tables and figures; to all the GPs that have supported the commissioning of a FH service including Dr Andrew Douglas, Dr Andy Whitfield,

Dr Rosemary Croft and Dr Simon Goodwin; to Dr Ruth Milton, Director of Public Health in Hampshire, who championed commissioning this service; to Professor James Raftery at Southampton University who provided independent advice regarding our cost models; and to Mark Hackett, CEO of UHS (up to 2013), Dr Michael Marsh, Medical Director UHS and Dr Derek Sandeman, Divisional Clinical Director UHS, for their encouragement and support in this initiative.

Contributors RP drafted the initial version of the paper and revised the NICE costing template to incorporate the changes needed for the three alternative models of delivery and is the guarantor. MG extended the NICE model from 3 to 10 years, analysed data, wrote the online supplementary technical appendix and edited the paper. MW is the operational manager for the SHIP FH service and contributed to the content of the discussion and box 1. RW and DH helped design the three alternative models of delivery and helped develop local revisions to the costing template. BM commissioned the extension of the of the NICE costing template to 10 years, helped design the three alternative models of delivery and helped develop local revisions to the costing template. SB reviewed versions of the paper, contributed to the evidence base in the introduction and the content of the discussion. CDB was the academic lead for the study, helped design the structure of the paper, wrote much of the content of box 1 and has been principal editor of the paper. He is a guarantor.

Funding CDB is funded in part by the Southampton National Institute for Heath Research (NIHR), Biomedical Research Centre.

\section{Competing interest None.}

Provenance and peer review Not commissioned; externally peer reviewed.

Data sharing statement This study has no patient level data. Consent and ethical approval were not required. However, all data referred to in this paper can be shared. This includes revised NICE costing templates, 10-year evolutions of costs and the care pathways for the three alternative delivery models (specialist-led, dual-care and GP-led).

Open Access This is an Open Access article distributed in accordance with the Creative Commons Attribution Non Commercial (CC BY-NC 3.0) license, which permits others to distribute, remix, adapt, build upon this work noncommercially, and license their derivative works on different terms, provided the original work is properly cited and the use is non-commercial. See: http:// creativecommons.org/licenses/by-nc/3.0/ 


\section{REFERENCES}

1. NICE. Clinical guideline 71: identification and management of familial hypercholesterolaemia. NICE, 2008.

2. NICE. Familial hypercholesterolaemia: costing report, implementing NICE guidance. NICE, 2009.

3. Gill PJ, Harnden A, Karpe F. Easily missed? Familial hypercholesterolaemia. BMJ 2012;344:e3228.

4. Allaby M, Griffin M. Implementation of the NICE clinical guideline CG71 on familial hypercholesterolaemia: a report for the South Central Cardiovascular Network. Public Health Resources Unit, October 2009. http://heartuk.org.uk/FHToolkit/downloads/3.3/3C\%20South\%20Central \%20Cardiac\%20Network\%20example.pdf Last viewed 27 Jan 2014.

5. Heart UK. Saving lives, saving families: the health, social and economic advantages of detecting and treating familial hypercholesterolaemia (FH). Heart UK, 2012.

6. Heath KE, Humphries SE, Middleton-Price $\mathrm{H}$, et al. A molecular genetic service for diagnosing individuals with familial hypercholesterolaemia (FH) in the United Kingdom. Eur J Hum Genet 2001;9:244-52.
7. Marks D, Thorogood M, Neil SM, et al. Cascade screening for familial hypercholesterolaemia: implications of a pilot study for national screening programmes. J Med Screen 2006;

13:156-9.

8. London Ideas. Department of Health familial hypercholesterolaemia cascade testing audit project: recommendations to the Department of Health. London Ideas, 2007.

9. DH Cardiovascular Disease Team. Cardiovascular disease outcome strategy: improving outcomes for people with or at risk of cardiovascular disease. Department of Health, 2013.

10. NICE. QS41: quality standards for familial hypercholesterolaemia. NICE, 2013. http://publications.nice.org.uk/familialhypercholesterolaemia-qs41 last viewed 27 Jan 2014.

11. NICE. Familial hypercholesterolaemia: costing template. NICE, 2009. http://guidance.nice.org.uk/CG71/CostingTemplate/xls/English last viewed 27 Jan 2014.

12. Shen L, Peng H, Xu D, et al. The next generation of novel low-density lipoprotein cholesterol-lowering agents: proprotein convertase subtilisin/kexin 9 inhibitors. Pharmacol Res 2013;73:27-34 